\title{
Degradation of reclaimed peat soils
}

\author{
Olga Zakharova ${ }^{1}$, Dmitry Kucher ${ }^{2}$, Konstantin Evsenkin ${ }^{3}$, and Farrukh Musaev ${ }^{1}$ \\ ${ }^{1}$ FSBEI HE "Ryazan SATU Named after P.A. Kostychev”, 1, Kostychev Str., Ryazan, 390044, \\ Russia \\ ${ }^{2}$ Peoples Friendship University of Russia (RUDN University), Faculty of Ecology, 6 Miklukho- \\ Maklaya Street, Moscow, 117198, Russian Federation \\ ${ }^{3}$ FSBSI "VNIIGiM Named after A.N. Kostyakov", 44, Building 2, Bolshaya Akademicheskaya Str., \\ Moscow, 127550, Russia
}

\begin{abstract}
The article presents the results of studies of the water-physical properties of reclaimed peat soils of four objects of Ryazan region, included in Ryazan Meschera. Drainage systems are destroyed due to lack of maintenance, which leads to an increase in the level of groundwater in the drained areas. The peat soils of the objects have similar changes, expressed in the utilization of peat over 65 years of drainage by $28-38 \%$, soil compaction by $0.08-0.12 \mathrm{~g} / \mathrm{cm} 3$, a decrease in the ash content of peat by $2-2.9 \%$ and a decrease in the thickness of the peat layer by $18-31 \mathrm{~cm}$.
\end{abstract}

\section{Introduction}

"An urgent task of science and industrial workers in modern conditions is the survey and inventory of previously built irrigation and drainage systems", - academician B.S. Maslov noted in the early 2000s [1]. One can agree with this statement, because the drainage systems built in the mid-1950s with the aim of expanding agricultural areas and the ones operating now on the territory of Ryazan Meschera are in an unsatisfactory state $[2,3]$. Drainage systems are included in reclamation facilities Tinki-II, Makeevsky Cape, Nikitskoye, Vozha of Ryazan and Klepikovsky districts, where the authors' monitoring studies have been carried out. The reclamation fund of Ryazan district is a little more than 16 thousand hectares, of which drained ones are 6,178 thousand hectares. Klepikovsky district has just over 20 thousand hectares, of which drained ones are almost 15 thousand hectares. The study of long-term drained soils in the region is poor. Until the end of the 1990s, the employees of the Meshchersky branch of VNIIGiM paid attention to the changes taking place.

\section{Objects and methods}

The purpose of the research is to study the water-reclamation properties of drained peat soils of Ryazan and Klepikovsky districts of Ryazan region [4].

The objects of research are drainage systems of the four listed objects and long-term drainage peat soil. The survey route has been compiled on the basis of an analysis of VNIIGiM reports for a long-term period. Peat soils are currently not used for agricultural 
purpose. Only $5 \%$ of the meadow at Tinki-II site has been leased by Novoselki agricultural holding since 2019 for the purpose of producing haylage from vetch-oat grass mixture.

Drainage systems were monitored visually by comparing the current state of open main canals and collectors, upland catchwaters (Fig. 1), hydraulic structures, operational and road networks. The drainage network is now unilateral by the nature of the impact on the water regime of the drained area, that is, it serves only to drain excess water. Irrigation by Fregat machines was introduced at Tinki II facility in the mid-1980s and was used until the end of the 1990s. [5, 6].

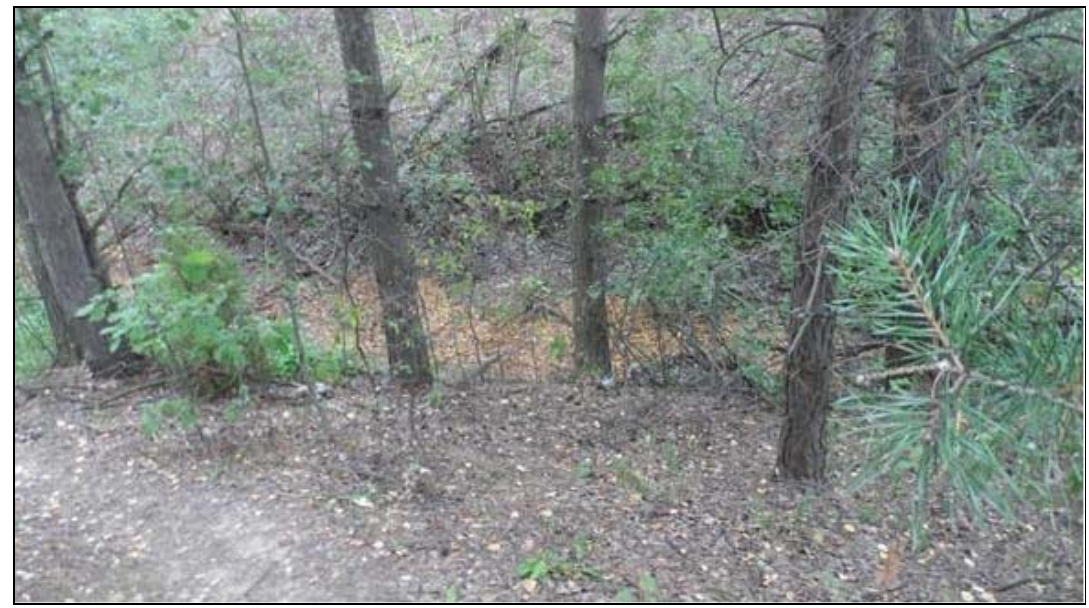

Fig. 1. The bottom of the upland catchwater.

The soil of the objects is peaty of lowland bogs and the level of groundwater is from 100 to $127 \mathrm{~cm}$. Soil samples have been taken with a soil drill by the envelope method in areas of 10x10 m (Fig. 2). The groundwater level was measured with a plopper in closed observation wells. The thickness of the peat layer was measured in natural conditions during the excavation of pits.

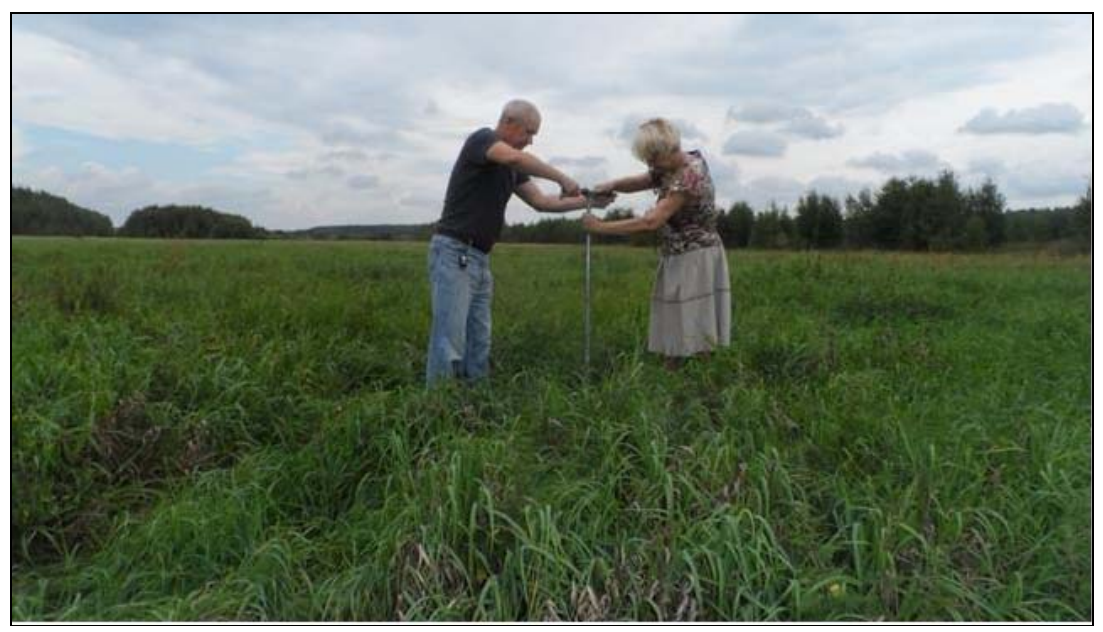

Fig. 2. Soils sampling.

The research methodology was generally accepted. The durability of peat soils was determined by the formula of A.S. But-Gusaim (1978). 
The annual peat decrease was calculated using GOST 10650-2013 Peat. Methods for determining the degree of decomposition (Reprinted with amendment) by the formula:

$$
\mathrm{h}_{\mathrm{c}}=\left(\mathrm{A} / \mathrm{B}^{\mathrm{x}}\right)+\mathrm{C}
$$

where hc - is the loss of peat, $\mathrm{cm} /$ year,

$\mathrm{x}$ - exponent, directly related to the time elapsed after the drainage of the swamp,

A, B, C - a value that depends on the type of agricultural land use (in our case, 0.8).

The ash content of peat in the arable layer, depending on the duration of drainage, was obtained by calculating according to the equation of V.M. Zubets, V.I. Dubrava (1974) with the introduction of a correction factor.

The density of undisturbed soil along the genetic horizons in triplicate was determined by the drilling method in the field with natural composition with caverns, cracks and voids inherent in the soil. The sample was weighed, the soil moisture was determined, and the density was calculated using the generally accepted formula:

$$
\rho=m_{1} * 100 /(100+W) V_{b}
$$

where $\mathrm{m}_{1}$ - is the mass of soil from a drill with natural atmospheric humidity $\mathrm{W}, \%$, $\mathrm{V}_{\mathrm{b}}$ - is the volume of a drill, $\mathrm{cm}^{3}$.

The reliability of the research is confirmed by processing the results using STATISTIK 10 computer program. Using the computer program Statistica 10, we identified the dependence of the moisture content of peat soil on the hydrothermal coefficient (HC), determined the ordination diagram of meadow areas and the ordination diagram of herbaceous plants in the space of two axes associated with the species of meadow grass dominants.

Weather conditions in 2010-2020 were characterized by Selyaninov's different-quality hydrothermal coefficients equal to 0.6 in 2010 and to 1.2 in 2019.

From the history of reclamation facilities, it is necessary to highlight their period of validity for 60-65 years, their use in the past as fodder lands and the cultivation of grain, vegetables, arable crops. Currently, meadow grasses are not used in agriculture. The water supply of the facility is atmospheric-ground. The drainage flow is regulated by a sluiceregulator. Now, in some sections of the main canals, sluices have been dismantled (Fig. 3).

Peat fires are observed annually.



Fig. 3. General view of the section of the main canal and the concrete structure of the dismantled sluice. 


\section{Results and discussion}

It has been established that deformations and destruction are currently observed on the drainage systems of four objects under the influence of anthropogenic and natural causes: destruction of canal slopes, bulging of soil in the lower parts of the slopes, erosion of the bottom and slopes, siltation and overgrowing with tree and shrub vegetation, destruction of bridges and pipe crossings and others. There was no control of drainage systems and their maintenance at the time of monitoring studies (2010-2020).

Results of monitoring of reclaimed peat soils when compared with the initial data of 1955-1960 showed peat decrease at all investigated ameliorative objects (Table 1), the appearance of leaks, indicating secondary waterlogging and an increase in ash content. The variability of the soil cover within the same area was established: the average depth of peat occurrence was on average $41 \mathrm{~cm}$; the minimum value was $26 \mathrm{~cm}$ and the maximum value was $80 \mathrm{~cm}$. Since 1952, the surface of the peat deposit has dropped by $1.2-1.9 \mathrm{~m}$.

Table 1. Characteristics of peat soil in the arable layer.

\begin{tabular}{|c|c|c|c|c|c|}
\hline \multirow{2}{*}{ Object } & \multirow{2}{*}{$\begin{array}{c}\text { Peat } \\
\text { decrease, } \\
\mathbf{h}_{\mathrm{c}}, \mathrm{cm}\end{array}$} & \multirow{2}{*}{$\begin{array}{c}\text { Peat } \\
\text { sediment, } \\
\text { cm/year }\end{array}$} & \multirow{2}{*}{$\begin{array}{c}\text { Volumetric } \\
\text { weight of the } \\
\text { upper part of } \\
\text { the profile, } \rho \text {, } \\
\text { g/cm }{ }^{3}\end{array}$} & \multicolumn{2}{|c|}{ Peat characteristics } \\
\hline & & & & $\begin{array}{c}\text { Peat density } \\
\text { coefficient }\end{array}$ & Gradation \\
\hline Tinki -II & 49 & 0.5 & 0.22 & 1.25 & $\begin{array}{l}\text { Medium } \\
\text { looseness }\end{array}$ \\
\hline Vozha & 68 & 0.7 & 0.38 & 1.20 & Dense \\
\hline Nikitskoye & 60 & 0.6 & 0.30 & 1.28 & $\begin{array}{l}\text { Medium } \\
\text { looseness }\end{array}$ \\
\hline $\begin{array}{c}\text { Makeevsky } \\
\text { Cape }\end{array}$ & 64 & 0.6 & 0.32 & 1.25 & $\begin{array}{l}\text { Medium } \\
\text { looseness }\end{array}$ \\
\hline
\end{tabular}

So peat decrease averaged $0.77 \mathrm{~cm}$ per year. Peat decrease was $28 \%$ less at Tinki-II site that was explained by the maintenance of a stable soil condition by bilateral regulation of the water regime (drainage, irrigation in the past and sluicing until 2018).

Reducing the calculated total to $0.6 \mathrm{~cm} /$ year is an important problem of preserving organic matter. The ratio of 1.2:1.0 when comparing theoretical and actual values is explained by the creation of a looser structure with double humidification at Tinki-II site in previous years when using the meadow as forage land.

Peat sediment coefficient $K_{o}$ at a depth of 0.1-0.6 $\mathrm{m}$ is from 0.67 (loose density) to 0.82 (medium density).

Soil density increased from $0.10 \mathrm{~g} / \mathrm{cm}^{3}$ at Tinki-II site occupied by meadow grasses, due to the compaction of the upper layer. At reclamation sites Vozha and Nikitskoye, the increase in density was $0.20-0.12 \mathrm{~g} / \mathrm{cm}^{3}$, respectively. At Makeevsky Cape, this indicator increased by $0.08 \mathrm{~g} / \mathrm{cm}^{3}$.

The average ash content of peat at reclamation facility Tinki-II was $12.1 \%$ in the $0-5$ $\mathrm{cm}$ layer. It was $11 \%, 11.8 \%$ and $11.5 \%$ at Vozha, Nikitskoye and Makeevsky Cape, respectively, with significant fluctuations along horizons, which is typical for transitional peat. So the optimal values of the indicators of peat soil are the following ones: the degree of decomposition is from 20 to $50 \%$; ash content is from 11.5 to $14.5 \%$ and bulk density is from 0.15 to $0.23 \mathrm{~g} / \mathrm{cm}^{3}$. As for their values of more than $50 \%$, they are critical and peat soil, at the same time turns into a humified mass, which, with further use, degrades more and more, that can lead to complete exhaustion of peat soil. 
The durability ( $t$ ) of a meter layer of peat soils, calculated by formula of A.S. ButGusaim is shown in Fig. 4.

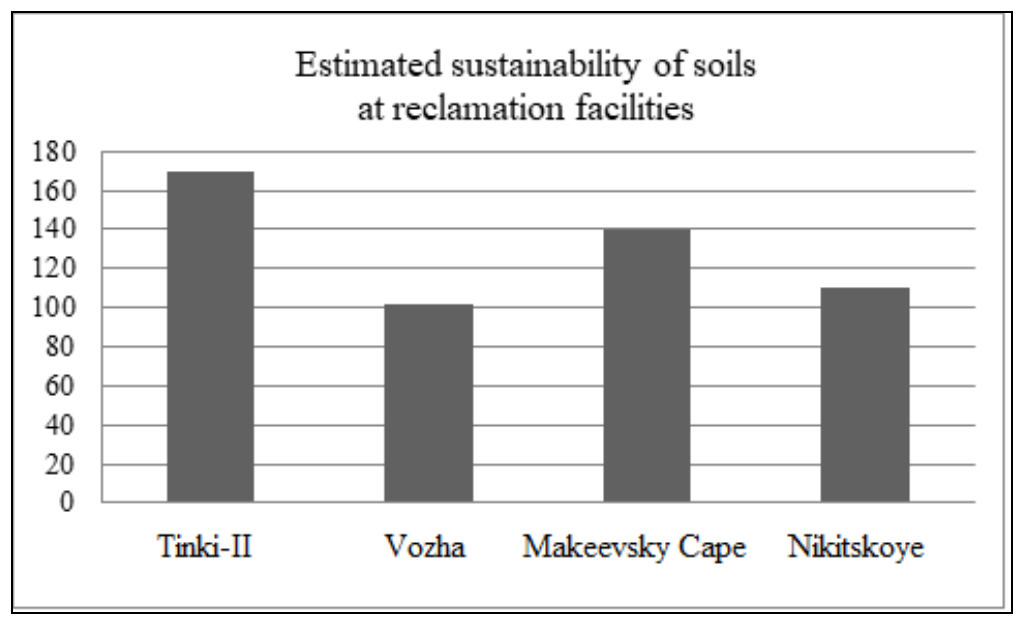

Fig. 4. Estimated sustainability of soils.

Considering that for about 20 years the land reclamation systems have functioned without control, and there have not been any agricultural activities in the territories, the value of sustainability of peat soils at the facilities will not decrease. Tinki-II facility has a higher indicator, that is explained by better conditions for crops when bilateral regulation of the water regime of soils in the past.

The thickness of the peat layer, determined by the sounding method, at Tinki-II facility was $156 \mathrm{~cm}$ in $1955,138 \mathrm{~cm}$ in 2000 and $116 \mathrm{~cm}$ in 2020. This parameter at Vozha facility was $132 \mathrm{~cm}$ in 1960 and $106 \mathrm{~cm}$ in 2020, while it valued $129 \mathrm{~cm}$ in 1960 and $96 \mathrm{~cm}$ in 2020 at Nikitskoye facility, and it was $138 \mathrm{~cm}$ in 1960 and $116 \mathrm{~cm}$ in 2020 at Kalskoye facility.

\section{Conclusion}

Thus, summarizing the research results, signs of degradation of the reclaimed peat soils of Tinki-II, Vozha, Nikitskoye and Makeyevsky Cape facilities were revealed, which manifested itself in peat drainage by $28-38 \%$ over 65 years, soil compaction by $0.08-0.12$ $\mathrm{g} / \mathrm{cm}^{3}$, a decrease in the ash content of peat by $2-2.9 \%$ and a decrease in the thickness of the peat layer by $18-31 \mathrm{~cm}$. To improve water-reclamation properties of the soils of the objects, it is necessary, first of all, to equip drainage canals, restore their slopes and drops and to clear the bottom to maintain the optimal speed of water movement in them, to repair the sluices.

\section{References}

1. B.S. Maslov, Reclamation of peat bogs (2006)

2. D.V. Vinogradov, E.A. Vysotskaya, K.V. Naumtseva, \& E.I. Lupova, IOP Conference Series: Earth and Environmental Science, 422, 012014 (2020)

3. D.V. Vinogradov, M.P. Makarova \& M.M. Kryuchkov, Int. Conf. on World Technological Trends in Agribusiness IOP Conf. Series: Earth and Environmental 
Science, The use of mineral fertilizers in sunflower crops in the conditions of Ryazan region, 624, 012077 (2020)

4. U.A. Vladimirova, S.G. Shurygin, Actual problems in forestry: materials of the III international. scientific-practical Conf of Young Scientists, November 06-08, 2019 St. Petersburg, 221-223 (2019)

5. A.I. Dunaev. Impact assessment and environmental protection measures for draining agricultural lands (Pub. house of the Bryansk State Agricultural Academy, Bryansk, 2013)

6. E. Lupova, D. Vinogradov, O. Zaharova, D. Kucher, BIO Web of Conferences, 27(2), 00014 (2020) 